\title{
The Driving Factors of Public's Interest in The Use of QRIS to Achieve Cashless Society
}

\author{
Risky Angga Pramuja ${ }^{1, a^{*}}$; Arif Prasetyo Wibowo ${ }^{2, a ;}$ Dedik Fitra Suhermanto ${ }^{3, a}$ \\ 1riskyanggapramuja@umm.ac.id; 2arifpwibowo@umm.ac.id; 3dfsuhermanto@umm.ac.id \\ aUniversitas Muhammadiyah Malang \\ *corresponding author
}

\section{ARTICLE INFO}

Article History

Received : 12-08-2021

Revised : 10-09-2021

Accepted : 13-09-2021

Keywords

QRIS

Oro - Oro Dowo Market

Theory Acceptance Model (TAM)

Traditional

Modern

\section{ABSTRACT}

The market serves as a traditional market that has been renovated by the local government to transform the traditional system into a modern market without abandoning its traditional traits. On the other hand, the modern system refers to improved sanitation and payment mechanisms. The payments in traditional markets have been done by using cash, but the modern market system promotes non-cash payments. In this case, the non-cash payments are implemented using a barcode scanning system provided by the Indonesian national bank under the name QRIS. Therefore, an in-depth study was essential to be carried out to understand the public's interest in the use of QRIS or non-cash for transactions in the Oro-Oro Dowo Market. The research methods used in this study were field research and survey. For the data analysis, several theories were applied, namely Theory of Reasoned Action (TRA), Theory of Planned Behaviour, and Technology Acceptance Model (TAM). Then, the theories were analyzed by utilizing a software called SMART PLS to identify whether there was a correlation and effect of the use of QRIS and the buying interest or transaction rates in the Oro-Oro Dowo Market. The results of this study indicate that the three variables of reliability, construct validity, structural model, and discussions related to complexity, the usefulness of QRIS, time constraints, ease of use, and e-learning self-efficiency show appropriate consistency as most of the respondents used QRIS as an electronic transaction system that allowed them to do a faster transaction due to its efficiency and accessibility.

This is an open access article under the CC-BY-SA license.

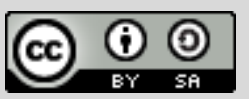

\section{Introduction}

Advanced information technology has reached the more modern transaction system in the market. The modern transaction system had become one of the researchers' considerations in this study which focused on changes in consumers' behavior concerning transactions in traditional markets. In this research, the researchers selected Oro-Oro Dowo Traditional Market, Malang as the object of the study. This selection was based on the 
behavioral aspects of local customers who often make modern transactions in Oro-oro Dowo Market using an online payment system, namely QRIS (Quick Response Indonesia Standard). This payment method utilizes barcode scanning that is affiliated with an application on smartphones or mobile phones (Luarn, 2005).

According to the Indonesian Ministry of Communication and Information Technology, there were 78 active e-commerce platforms in 2018, which are supported by 82 million internet users in Indonesia (Kemkominfo, 2019). In response to the rapid flow of the global market system, the government currently had set its sights on Indonesia becoming the largest digital economy by 2020. As reported by Bank Indonesia, the government will implement the QRIS payment model and require all providers of payment system services (PSS) to employ this online payment method in order to advance the economy in keeping with global economic developments (Catriana, 2019).

According to the Global Web Index data summarized by We Are Social and Hootsuite, the number of Indonesians who made online shopping transactions in December 2018 had reached $86 \%$ of the total 264 million Indonesian population or around 227.04 million people (Kemp, 2018). Furthermore, the Association of Indonesian Internet Service Providers (APJII) released the results of a survey conducted on April 14, 2019, with 5900 samples and a margin of error of $1.28 \%$ (Pratomo, 2019). They stated that the number of internet users in Indonesia had grown to $10.12 \%$. The result also shows that 171.17 million people or around $64.8 \%$ of the population were already connected to the internet (Pratomo, 2019). Based on this percentage, it can be interpreted that half of the total population in Indonesia has the internet as a part of their daily lives, not to mention as a medium for economic transactions. Payment methods using QRIS have better transaction advantages compared to cash. Examples of the advantages of QRIS are that there is no need to give change, it is effective, time efficient, and avoids physical touch between merchants and customers.

Based on the government's vision of Indonesia becoming the largest digital economy by 2021, it is important to involve financial technology as a part of transaction media in society. In this case, traditional markets as one of PSPs (payment service providers) can be an interesting benchmark and study in how they adjust to the current development of financial technology. If the traditional markets (McKechnie, 2006), can adapt to the demands of modern development, it means that the distribution of financial technology has reached all levels of society. The expected result is that Indonesia can become the largest digital economy. 
The objective of this study is to investigate the driving factors of the public's interest in using QRIS as a non-cash payment method with smartphone applications(Yu, 2012). These factors are measured by employing TAM (technology acceptance model) with the addition of exogenous variables. TAM features Perceive Fullness and Perceived Ease of Use as measurement indicators related to the use of QRIS (Lee, 2001). These two factors are based on three variables, namely the experience using the smartphone's application, the reputation of the technology used, and flexibility or the ease of using the technology.

Based on the above-mentioned background, it is necessary to study the public's interest in using QRIS to do transactions in the Oro-Oro Dowo Market. Meanwhile, the lack of QRIS usages as a payment method is commonly found in traditional markets in Indonesia. Therefore, this research was carried out in order to measure the adaptation of the use of QRIS in transactions in the Oro-Oro Dowo Market.

\section{Method}

This research is categorized as descriptive quantitative research using primary data. Then, a cross-section data and Technology Acceptance Model (TAM) are applied as the research method and the research design respectively (Wong, 2013). TAM as a theory can be used to elaborate individual acceptance of the use of information technology systems (Hartono, 2018). The TAM's theory employed in this study is an extension of the original theory by adding external factors, namely complexity, e-learning self-efficacy, and time constraints.

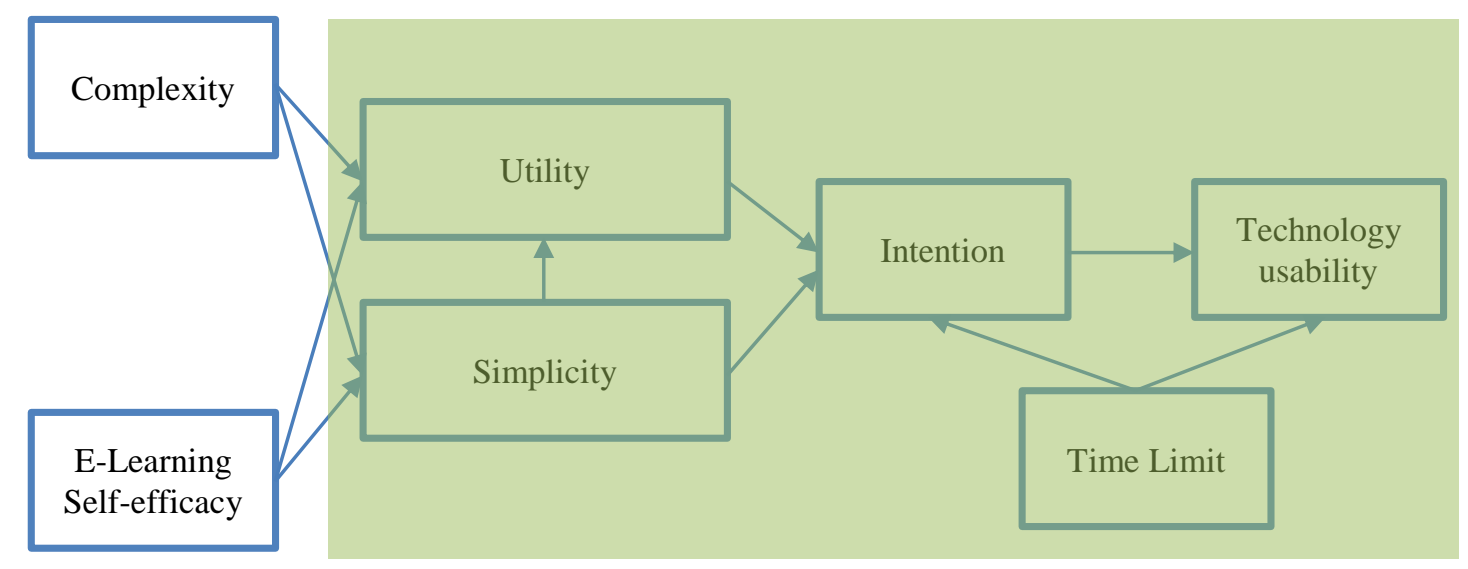

Figure 1. Research Framework

The data used in the research were primary data obtained directly from the selected respondents. The primary data was collected by conducting face-to-face interviews using a set of questions complemented with direct observation in the field. The purposive sampling method was carried out on several visitors in the Sengkaling Recreation Park in Malang, 
Indonesia. According to (Soeratno \& Arsyad, 2008), purposive sampling consists of a carefully selected sample so that it is relevant to the research design. It is done by methodically selecting people based on specific characteristics possessed by the sample.

The number of samples was determined and calculated according to (Fraenkel, 1993) suggestions: 1) 100 samples for descriptive research, 2) 50 samples for correlational research, 3) 30 participants per group for causal-comparative research, and 4) 30/15 participants per group for experimental research. Measuring the attitude of respondents in this study used a Likert scale with four levels, namely a value of 1 is "strongly disagree", a value of 2 is "disagree" value, a value of 3 is "agree", and a value of 4 is "strongly agree"

(Malhotra, 2005) provides guidance for the sample size consideration by multiplying the number of variables by 5 , or $5 x$ the number of variables. Thus, if the number of observed variables is 20 , then the minimum sample is $5 \times 20=100$ questionnaires. In addition, this study employed a survey method using questionnaires. They contained structured questions consisting of 2 (two) parts, namely: 1) part A asking about the characteristics of respondents, 2) part B asking about visitors' perceptions of their interest in using the QRIS system to do transactions in the Oro-Oro Dowo Market in Malang.

To answer the questionnaire, the researcher guided and interviewed the respondents to fill out each part of the questionnaire. The operational definition is a complete set of instructions about what to observe and how to measure a variable or the concept of an operational definition that can help to classify phenomena into specific categories of variables.

The research testing entailed validity test, reliability test, and partial least square (PLS) analysis. 1) Validity Test. Validity is the extent to which a measuring instrument can accurately measure what it wants to measure. A valid instrument means that the instrument can measure what should be measured (Sugiyono, 2016). The data validity test aims to determine the validity of the data obtained from the questionnaires. 2) Reliability Test. The reliability test is a measurement of a respondent's stability and consistency in answering a question. The reliability test is usually formulated with Cronbach alpha $(\alpha)$. According to (Sugiyono, 2016), the results of the reliability test should be as follows: a) Cronbach alpha $<0.6$ (poor reliability), b) Cronbach alpha 0.6 - 0.79 (accepted reliability), c) Cronbach alpha 0.8 (good reliability). 3) Partial Least Square (PLS) analysis. Partial Least Square (PLS) is an alternative method of analysis using variance-based Structural Equation Modeling (SEM). PLS can be used on any type of data scale (nominal, ordinal, interval, and ratio) and has more flexible assumption requirements. Additionally, a software application called SMARTPLS was employed to estimate this variance-based Structural Equation Modeling 
(SEM) (Ghozali, 2016). One of its advantages is that it does not require assumptions and can be estimated with a relatively small number of samples. Accordingly, this study aimed to predict and elucidate the correlation between constructs and to comprehend the meaning of the four constructs with a complex model and a relatively small sample size between 30 to 100 respondents (Ghozali, 2016).

PLS data analysis essentially involves two processes, namely the outer model (measurement model) and the inner model.

1) The outer model (measurement model) specifies the correlation between latent variables and their indicators. In other words, the outer model defines how each indicator relates to its latent variables. The tests involve Convergent Validity and Discriminant Validity. Convergent validity value is the loading factor value on the latent variable with its indicators. Meanwhile, discriminant validity is the cross-loading factor value that is useful for distinguishing whether a construct has a discriminant mark, particularly by comparing the loading value on the intended construct that has a higher number than the loading value in other constructs.

a) Average Variance Extracted (AVE). The expected AVE value is higher than $\geq 0.5$.

b) Composite Reliability. Data having $\geq 0,7$ composite reliability is considered to have high

reliability. Composite reliability is performed to test reliability by examining the composite reliability value of the indicator block that measures variables. The result of composite reliability will show a satisfactory value if it is above 0.7 .

c) Cronbach Alpha. The reliability test is strengthened by Cronbach Alpha. The expected value is $\geq 0.5$ for all constructs.

2) Inner model is employed to analyze the correlation between latent constructs. There are several tests for the structural model, namely:

a) $R$ square on the endogenous construct. The $R$ square value is the determination coefficient on the endogenous construct. $\mathrm{R}$ square value is categorized into 0.67 (strong), 0.33 (moderate) and 0.19 (weak).

b) Estimate for Path Coefficient. It measures the path coefficient or the magnitude of the correlation of latent constructs by implementing the Bootstrapping procedure.

c) Effect Size (f square). It examines whether a model is good or not.

d) Prediction relevance ( $Q$ square) otherwise known as Stone-Geisser's. This test determines the predictive capability by implementing a blindfolding procedure. Its values are categorized into 0.02 (small), 0.15 (medium) and 0.35 (large). It can only be done for endogenous constructs with reflective indicators. 


\section{Results and Discussion}

The research analysis results explain the evidence of reliability, construct validity, structural model, and discussions. These three analyses show the consistency of the current measurement model. Furthermore, the measurement model emphasizes the complexity level, the usefulness of QRIS, actual technology use, time constraints, ease of use, and elearning self-efficiency by conducting PLS-SEM path analysis. Finally, the discussion section attempts to correlate the findings to previous studies related to this research. The following are the details of the results of the PLS-SEM analysis.

Research (Widayat et al., 2020) on the factors that influence the adoption of e-money payments, such as time efficiency, practicality, and operational ease driven by supporting facilities from supporting stakeholders, the banking sector, and good internet services . This can be used by entrepreneurs and stakeholders to innovate openly as an indicator to measure the success of e-money payment application innovation. Research conducted by (Juniarti Rosa Prafitri, 2018) with the topic of factors that affect Mobile Payment shows the results that the use of Mobile Payments is driven by perceptions of effectiveness, convenience and others in mobile transactions.

\section{Construct validity and reliability}

Construct validity and reliability tests aimed to examine the quality of the survey in which the results are expected to reflect stability in determining the measures and procedures used in the study. Based on the results of the analysis, the reliability analysis was assessed by utilizing composites and Cronbach Alpha. Moreover, this method is an evaluation of the assessment reliability by calculating the composite value 0.7 which requires Cronbach Alpha to interpret the results (Hajli et al., n.d.). According to graph 1 below, the resulting construct has met the cut-off value of the reliability value. The composite reliability cut-off value must be less than 0.7 , and the cut-off value in the Cronbach Alpha is $>0.68$.

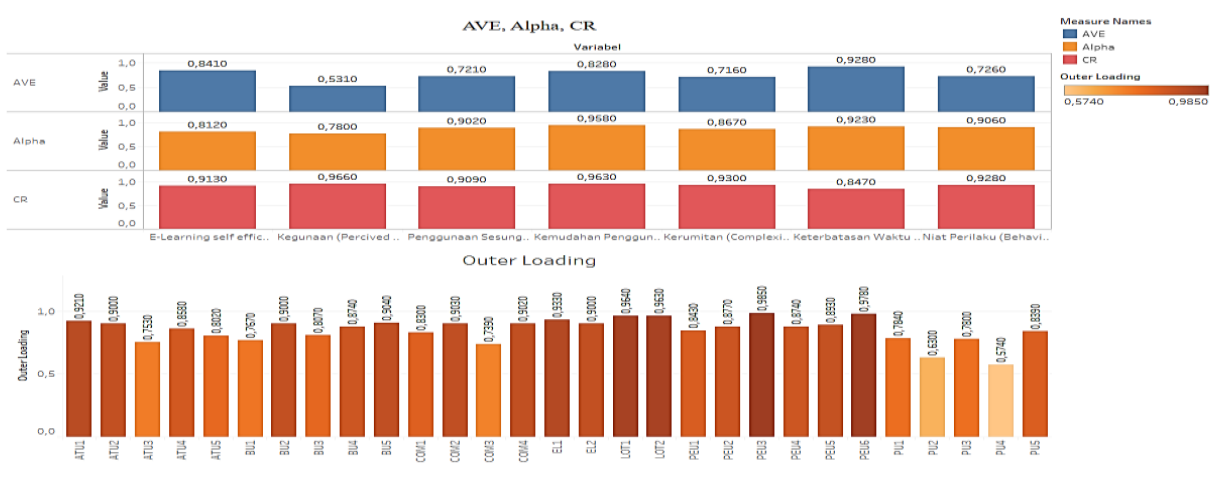

Figure 2. Construct Validity and Reliability 
The results of the validity test of the questionnaire should be able to describe the ability of the item to measure the phenomenon to be studied. The validity measurement applies these two methods, namely convergence of validity and discriminant validity. Based on Graph 1, the convergent validity is observed from the results of the Average Variance Extracted (AVE). The cut-off value of AVE is set to "> $0.5 "$ in which all constructs have achieved the cut-off value. Furthermore, the result of the discriminant validity test in Graph 2 indicates that the constructs have met the Fornell-Larcker criteria. In other words, the cross-diagonal results should be higher than the off-diagonal (Harrison et al., n.d.) and (Wong, 2013). The following are the results of coding and construct analysis in a graphic image:

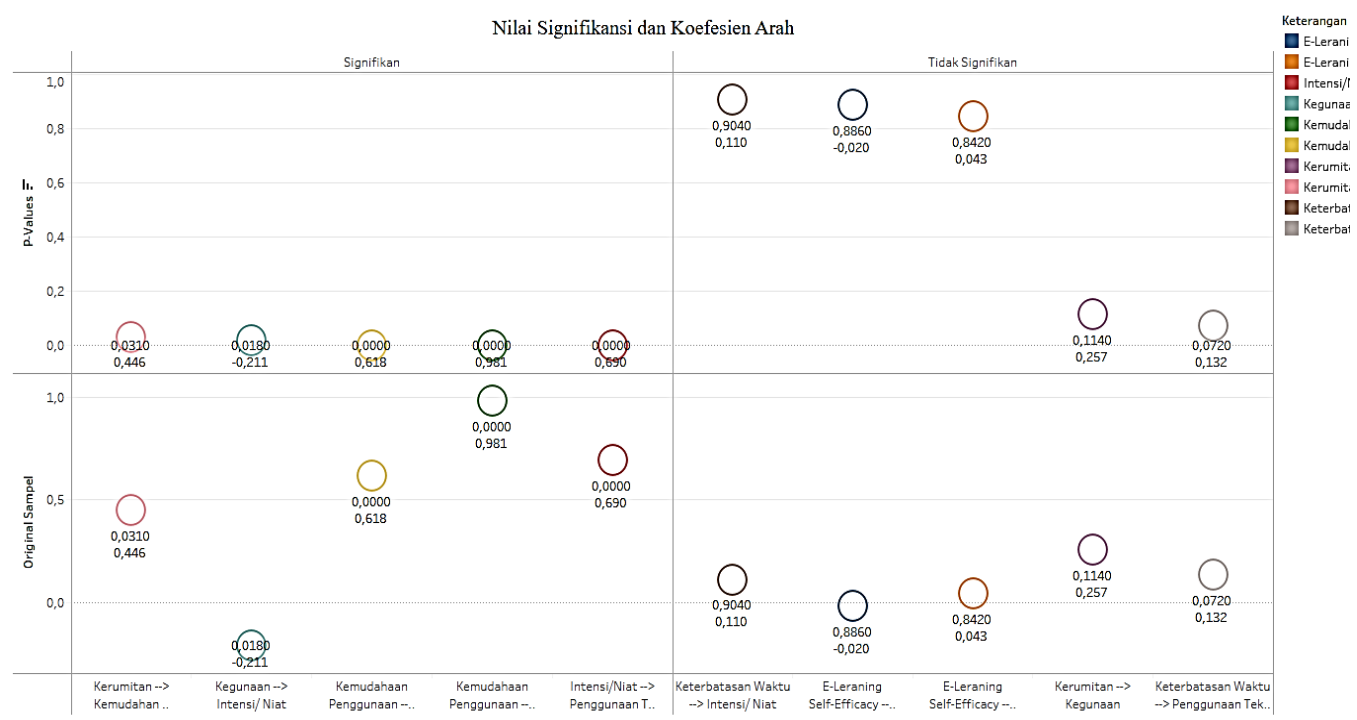

Figure 3. Coding and Construct Analysis Results

\section{Model Measurement}

The results of the PLS path analysis in Figure 2 were obtained by exercising ten hypotheses. It illustrates that five hypotheses show a significant effect, whereas the others showed an insignificant effect at the 0.05 level. Furthermore, the proposed construct's ability to explain the causal variables in the outcome variables was assessed using correlation and path coefficients. The significance coefficient measures the correlation among intention, usefulness, ease of use, and actual technology use. The significance of the analysis results indicates that the intention variable is $77 \%$ with the correlation between ease of use and usefulness variables. Specifically, the value shows a significant correlation because it is higher than the cut-off benchmark which is 0.5 . Then, the usability value is 58 percent more than the cut-off value which has a correlation involving complexity, e-learning self-efficiency, and ease of use. However, the model can only describe a 23 percent result. In 
addition, the analysis result of the ease-of-use variable shows a 23 percent result in the correlation between complexity and e-learning self-efficiency variables. Lastly, the actualtechnology-use (intension) variable shows a 56 percent result in the correlation between time constraints and intention variables. All in all, these results of the analysis are the PLS path model test where each variable has a different correlation coefficient. The difference is in the ease-of-use variable which only scored 23 percent of the complexity of using QRIS and e-learning self-efficiency.

Based on the PLS analysis, the correlation between e-learning self-efficacy and usefulness variables shows a negative direction of 0.884 or above 0.05 , which means it is not significant. The e-learning self-efficacy variable towards the ease-of-use variable shows a positive direction of 0.829 or above 0.05 , which means it is not significant. On the other hand, the actual-technology-use variable shows a positive direction of 0.000 or below 0.05 , which means it is significant. Moreover, the usefulness variable towards the actualtechnology-use variable is 0.015 or below 0.05 , which means it is significant. The ease-ofuse variable towards the actual-technology-use and the usefulness variables exhibits the same and significant result which is 0.000 or below 0.05 . The time constraint variable towards the actual-technology-use variable is 0.108 or below 0.05 , which means it is significant. In contrast, the time constraint variable towards the actual-technology-use variable is 0.059 , which means it is not significant. Additionally, the complexity variable towards the usefulness variable is 0.076 or less than 0.05 , which means it is not significant. Meanwhile, the complexity variable towards the ease-of-use variable is 0.016 or below 0.05 , which means it is significant. Here is the full image of the PLS path:

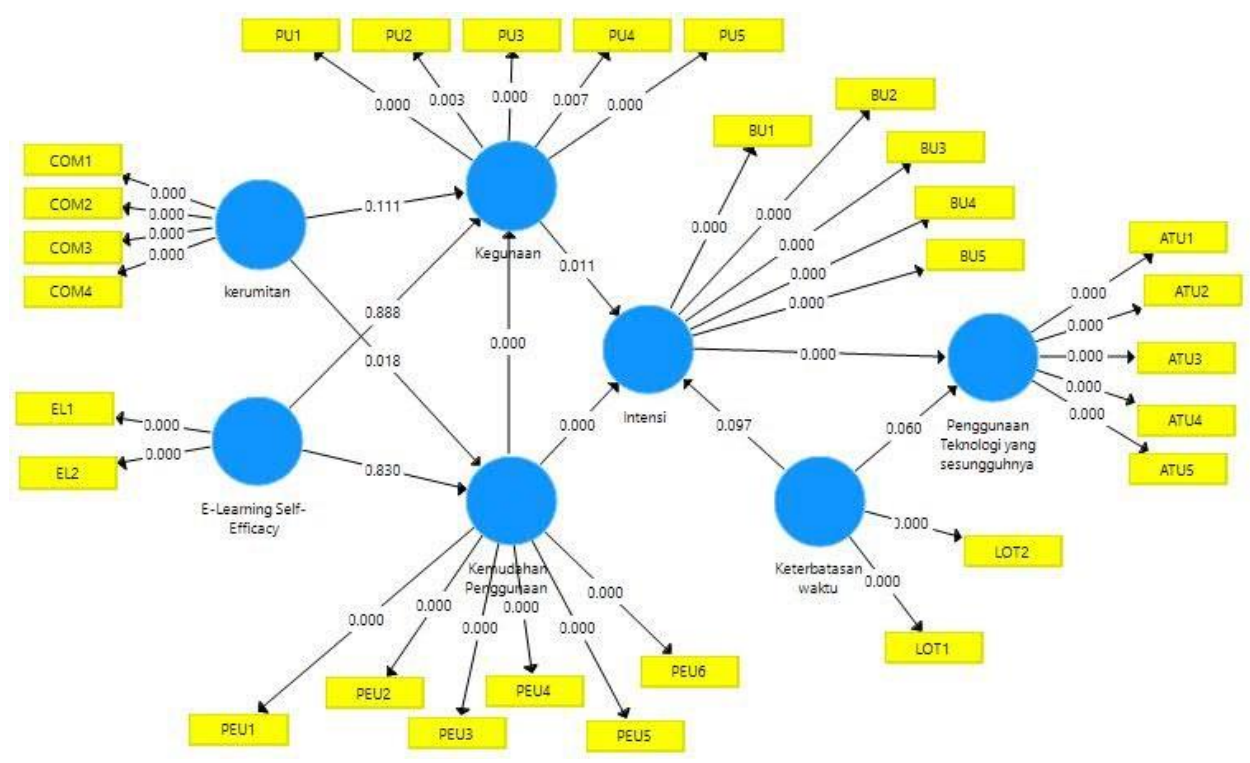

Figure 4. PLS Path 


\section{Conclusion}

The study of the actual technology use or TAM presents various perspectives, especially in understanding public interest or acceptance towards QRIS. Stakeholders of the Oro-Oro Dowo Market are expected to provide more literacy skills about QRIS particularly for customers in the Oro-Oro Dowo Market. This should be accomplished to make it easier for the customers to accept QRIS as a more modern transaction medium without abandoning the fundamental traits of traditional markets. The use of QRIS technology is influenced by the complexity factor of the ease of use, the usefulness quality that supports ease of use, and the ease of use of QRIS that is supported by intention and the intensity that promote the interest or acceptance towards the use of QRIS technology in the Oro-Oro Dowo Market.

This study offers several suggestions for future research. Firstly, it is necessary to conduct an in-depth confirmation through a study of the usefulness of QRIS in transactions within five years. In addition, it is suggested to explore more on the sustainability and usefulness of QRIS by obtaining a minimum of five years' worth of data to see the effectiveness of QRIS as a non-cash payment method in traditional markets. Furthermore, there is a need for similar research with different objects so that the issue of using QRIS can be applied as a pilot project in the development of modernized traditional markets without abandoning the traditional traits in the current era of globalization.

\section{REFERENCES}

Catriana, E. (2019). Bayar Nontunai Wajib Pakai QRIS Mulai 1 Januari 2020, Ini 4 Keuntungannya. Kompas.Com.

Fraenkel, J. (1993). How to Design and Evaluate Research in Education / 2nd ed. : Ill. : Bib.

Ghozali, I. (2016). Aplikasi Analisis Multivariete dengan Program IBM SPSS 23 (8th ed.). Badan Penerbit Universitas Diponegoro.

Hajli, N., Change, J. S.-T. F. and S., \& 2015, undefined. (n.d.). Social commerce: The transfer of power from sellers to buyers. Elsevier.

Harrison, D., Ajjan, H., ... J. H. J.-B. to the, \& 2018, undefined. (n.d.). Advanced Analytics: The Impact on Marketing and Evolution from Descriptive to Predictive. Societyformarketingadvances.Org.

Hartono, M. J. (2018). Metoda Pengumpulan dan Teknik Analisis Data.

Juniarti Rosa Prafitri. (2018). Faktor -faktor yang Mempengaruhi Penggunaan Mobile Payment : Sebuah Review Literature. Seminar Nasional Manajemen Dan Bisnis, 3, 526534.

Kemkominfo. (2019). Kemkominfo: Pertumbuhan e-Commerce Indonesia Capai 78 Persen. Kementerian Komunikasi Dan Informatika Republik Indonesia.

Kemp, S. (2018). Digital in 2018: World's internet users pass the 4 billion mark. We Are Social.

Lee, C. (2001). Internal capabilities, external networks, and performance: A study on technology-based ventures. Strategic Management Journal, 22(6), 615-640. https://doi.org/10.1002/smj.181

Luarn, P. (2005). Toward an understanding of the behavioral intention to use mobile 
banking. Computers in Human Behavior, 21(6), 873-891.

https://doi.org/10.1016/j.chb.2004.03.003

Malhotra, K. (2005). Riset Pemasaran (Pendekatan Terapan) (T. S. Rusyadi (ed.)). PT. Indeks Kelompok Gramedia.

McKechnie, S. (2006). Applying the technology acceptance model to the online retailing of financial services. International Journal of Retail and Distribution Management, 34(4), 388-410. https://doi.org/10.1108/09590550610660297

Pratomo, Y. (2019). APJII: Jumlah Pengguna Internet di Indonesia Tembus 171 Juta Jiwa. Kompas.Com.

Soeratno, \& Arsyad, L. (2008). Metodologi Peneitian Untuk Ekonomi dan Bisnis.

Sugiyono. (2016). Metode Penelitian Kuantitatif, Kualitatif dan R\&D. PT Alfabet.

Widayat, W., Masudin, I., \& Satiti, N. R. (2020). E-Money payment: Customers' adopting factors and the implication for open innovation. Journal of Open Innovation: Technology, Market, and Complexity, 6(3). https://doi.org/10.3390/J0ITMC6030057

Wong, K. K. K.-K. (2013). 28/05 - Partial Least Squares Structural Equation Modeling (PLSSEM) Techniques Using SmartPLS. Marketing Bulletin, 24(1), 1-32.

Yu, C. (2012). The investigation under technology acceptance model for the factors of using e-book among employees of a Taiwanese financial and insurance company. International Journal of Digital Content Technology and Its Applications, 6(3), 244253. https://doi.org/10.4156/jdcta.vol6.issue3.29 